\title{
Impactos da pandemia de Covid-19 no Sistema de Transporte Público por Ônibus em São João da Boa Vista - SP
}

Impacts of the Covid-19 pandemic in the Public Transportation System in São João da

$$
\text { Boa Vista -SP }
$$

Impactos de la pandemia Covid-19 en el transporte público urbano en São João da Boa

$$
\text { Vista - SP }
$$

Geisa Aparecida da Silva Gontijo Doutora em Engenharia Urbana, Ufscar, Brasil. geisaapgontijo@gmail.com

Weslei Augusto Pereira Junior Graduando em Engenharia Civil, UNIFEOB, Brasil. weslei.junior@sou.unifeob.edu.br

Pedro Henrique da Silva Sales Graduado em Engenharia Civil, UNIFEOB, Brasil. pedro.sales@sou.unifeob.edu.br 


\section{Revista Científica ANAP Brasil}

ISSN 1984-3240 - Volume 14, número 33, 2021

\section{INTRODUÇÃO}

Desde o início do ano passado, até o presente momento - 2021, o mundo passa por uma crise de saúde pública devido ao novo Coronavírus (Covid-19) que se propagou em escala global, causando diversos impactos que afetaram e continuam afetando o planeta. Diante desse cenário, várias cidades, por meio de seus setores econômicos, estão sendo prejudicadas. Dentre os setores atingidos, estão os sistemas de transportes públicos por ônibus. Desse modo, em São João da Boa Vista, isso não seria diferente, nossa cidade também sofre com a pandemia. Localizada na região Centro-Leste do Estado de São Paulo, Brasil, São João da Boa Vista possui uma população estimada, segundo o IBGE (2021) de 91.771 habitantes em 2020 e uma frota total de 69.913 veículos em 2018. Se considerarmos essa frota total, observamos que a cidade possui uma taxa de motorização elevada, sendo aproximadamente 0,76 veículos por habitantes.

Apesar de ser considerada uma cidade pequena, São João da Boa Vista já apresenta diversos problemas de trânsito e de transportes semelhantes às cidades de grande porte, sendo necessário um investimento efetivo nos modos de transportes mais sustentáveis.

Segundo as análises contidas na formulação do Plano Diretor (PMSBV, 2019), a baixa densidade dos novos bairros e a concentração de emprego na área central e distrito industrial condicionam um desenho de itinerários de transportes públicos deficitários, atendendo poucos usuários do transporte coletivo. Por isso, a cidade possui poucas linhas de transportes atendendo uma pequena parcela da população; além de não possuir um estudo de Origem/Destino (Matriz O/D), como exige um bom estudo da demanda por transportes. Outro aspecto que também reflete no sistema de transportes público da cidade é o seu traçado viário descontínuo e a presença de duas barreiras físicas - a Rodovia 342 e a linha férrea, acentuando o problema da segregação espacial e, consequentemente, a piora da mobilidade urbana.

De acordo com o previsto na Lei Complementar 4.516 de 20 de agosto de 2019 (PMSBV , 2019), o sistema de transporte coletivo de São João da Boa Vista pode ser operado pelo setor público ou pelo setor privado, compreendendo o serviço de transporte público e privado de passageiros. O transporte público de passageiros é dividido em duas modalidades - o transporte público coletivo e o transporte público individual. O serviço de transporte privado de passageiros, por sua vez, compreende modos de transportes, que permitem a realização de viagens particulares tratadas entre o operador e o passageiro.

O Sistema de Transportes Público por Ônibus - STPO pode ser analisado sob ótica da mobilidade urbana - uma alternativa de análise mais atual para o planejamento dos transportes urbanos. Nesse contexto, Kneib (2014) diz que a mobilidade urbana está relacionada às condições e oportunidades que a estrutura urbana, entendida como conjunto de atividades, funções urbanas e a maneira como se organizam e articulam espacialmente - e o sistema de transporte, entendido como conjunto de infraestruturas e modos de transporte, proporcionam, conjuntamente, à realização dos deslocamentos, viabilizando a realização das atividades urbanas.

Gomide (2006) ressalta ainda que a mobilidade compreende a facilidade de deslocamento das pessoas e bens na cidade, tendo em vista a complexidade das atividades econômicas e sociais nela envolvidas. Dentre essas atividades, destaca-se o transporte coletivo por ônibus, sistema citado acima, que em sua adequação proporciona à população, facilidades e melhorias na qualidade de vida devido ao fato de ser uma alternativa eficaz de locomoção, reduz a probabilidade de acidentes no trânsito, colabora com a sustentabilidade por diminuir o 


\section{Revista Científica ANAP Brasil}

ISSN 1984-3240 - Volume 14, número 33, 2021

número de automóveis individuais, ocupa menor área dentro do espaço urbano, dentre outros benefícios que facilitam a mobilidade urbana.

No que tange o atual quadro pandêmico, Lima et al (2020) destacam que o foco principal neste momento deve ser evitar a disseminação do COVID-19 para que não haja saturação do sistema de saúde. Nesse sentido, uma das medidas mais importantes adotadas pelos governos da maioria dos estados e cidades brasileiras é o isolamento social horizontal voluntário ou mandatório de pessoas que não desempenham atividades essenciais. Essas devem limitar sua circulação, permanecendo em casa e, se possível, exercerem atividades laborais remotamente.

Com base nessas restrições, verifica-se que o sistema de transportes público por ônibus está sendo diretamente afetado, pois ele é um sistema de transportes destinado ao atendimento coletivo e sustentável e, que agora, está inserido dentro de um contexto de restrições e distanciamento social, evidenciando assim uma ameaça de seu princípio básico, o "coletivo". Shenzhen Bus Group (2020) afirma que com o surto de COVID-19, as empresas de transporte enfrentarão desafios severos que a pandemia impõe às suas operações, ao mesmo tempo em que devem atender às demandas de transporte existentes.

Lima et al (2020) ressaltam que nem todos os usuários de transporte público podem trabalhar remotamente ou possuem veículo próprio para se locomoverem quando necessário. Ainda, para que muitos possam cumprir as medidas de isolamento social e ficarem em casa, muitos outros necessitam continuar trabalhando. Para milhares que precisam ser socorridos neste momento crítico, outros milhares como profissionais da saúde, cozinheiros, faxineiros, motoristas, funcionários administrativos etc. precisam chegar ao trabalho para garantir que a rede econômica funcione.

Segundo o portal G1- RJ (2020) o sistema de transportes públicos do Rio de Janeiro deve operar com as janelas abertas e sem ar condicionado durante o verão, com a finalidade de diminuir as chances de contaminação no interior dos veículos. No entanto, há alguns veículos que possuem janelas vedadas, funcionando somente com o uso de ar condicionado, o que evidencia necessidades de adequação mecânicas e de layouts dos veículos atuais.

Couto et al (2020) relatam em seu trabalho que alguns países têm aproveitado o atual momento para implantar soluções de baixo custo com a finalidade de viabilizar os deslocamentos e o distanciamento social necessário durante a pandemia.

Diante do exposto, este trabalho visa analisar o sistema de transporte público por ônibus de São João da Boa Vista, por meio de uma pesquisa realizada, remotamente, junto à empresa Rápido Sumaré, que opera na cidade desde 01 de março de 2015, atendendo à demanda de acordo com suas linhas e itinerários pré-estabelecidos.

\section{OBJETIVOS}

Analisar o impacto da pandemia de Covid-19 no sistema de transporte público por ônibus de São João da Boa Vista, no período de 2019 e entre abril de 2020 até janeiro de 2021, por meio das análises de fluxo de passageiros da empresa que opera neste município, relatando dados de antes e durante a pandemia. 


\section{METODOLOGIA}

Para a realização deste trabalho, foram analisadas as informações obtidas pela empresa de transporte coletivo por ônibus que opera em São João da Boa Vista-SP (Rápido Sumaré) de acordo com os tópicos abaixo:

- Envio de questionário à empresa para obtenção dos fluxos de passageiros antes e durante da pandemia;

- Sistematização de dados;

- Análise dos dados levantados.

\section{RESULTADOS}

A frota de ônibus em São João da Boa Vista é composta de veículos básicos com mínimo de 70 passageiros, sentados e em pé, incluindo área reservada para acomodação de cadeira de rodas ou cão-guia, peso bruto total mínimo de 16 toneladas e comprimento total máximo de 14 metros, conforme a tabela "Classes de Veículos" da Associação Brasileira de Normas Técnicas (ABNT) NBR 15570:2009.

Durante a pandemia do novo Coronavírus, a empresa divulgou uma grade especial para o transporte público da cidade, com 10 linhas de transportes, englobando diversos bairros e horários. A alteração estava em conformidade com o decreto municipal que declarou Estado de Emergência na Saúde Pública do município motivada pela pandemia do novo coronavírus (Covid-19) em 2020. Porém, mediante o questionário enviado para a empresa Rápido Sumaré em 2021, verificou-se uma queda brusca no número de passageiros da empresa, enfatizando que houve uma redução da demanda e, consequentemente, a redução das linhas disponíveis que hoje está operando apenas com 5 linhas, sendo elas: Linhas 01.1/04.1 (DER e $1^{\circ}$ de Maio); Linhas 02.1/14.0 (Jardim Ipê/Jardim das Rosas); Linhas 05.1/06.0 (V. Brasil e Durval Nicolau); Linha 09 (Bairro Alegre Via Veterinária) e Linha 10.0 (distrito Industrial).

\subsection{Fluxos de passageiros em $2019 / 2021$}

Na tabela 1 é possível ver os dados referentes à média de fluxo de passageiros diário, semanal, mensal e anual no ano de 2019 (antes da pandemia) e em abril de 2020 à janeiro de 2021 (momento atual), permitindo observar a redução brusca no fluxo de passageiros durante as restrições causadas pela pandemia. Enquanto que em 2019 o sistema operava com 5.967 passageiros/dia, no período de abril de 2020 à janeiro de 2021 passou a operar somente com 1.241 passageiros/dia, havendo uma redução de $79,2 \%$ do fluxo. Consequentemente, esse percentual se mantém em relação aos outros períodos, conforme observado na tabela 1.

Tabela 1 - Fluxo de Passageiros da Empresa Rápido Sumaré de São João da Boa Vista - SP.

\begin{tabular}{lcccc}
\hline \multicolumn{1}{c}{ Média } & Diário & Semanal & Mensal & Anual \\
\hline Antes da pandemia (2019) & 5.967 & 41.769 & 179.010 & 2.148 .120 \\
Durante a pandemia (Abril/2020 à Janeiro/2021) & 1.241 & 8.687 & 37.233 & 446.796 \\
\hline Queda de passageiros & $\mathbf{4 . 7 2 6}$ & $\mathbf{3 3 . 0 8 2}$ & $\mathbf{1 4 1 . 7 7 7}$ & $\mathbf{1 . 7 0 1 . 3 2 4}$ \\
\hline
\end{tabular}

Fonte: Empresa Rápido Sumaré (2021). 


\section{Revista Científica ANAP Brasil}

ISSN 1984-3240 - Volume 14, número 33, 2021

A figura 1 ilustra bem a grande redução no fluxo de passageiros, que em 2019 atuava em seu máximo (100\%) e passou a operar com apenas $20,79 \%$ do fluxo no período de abril de 2020 à janeiro de 2021.

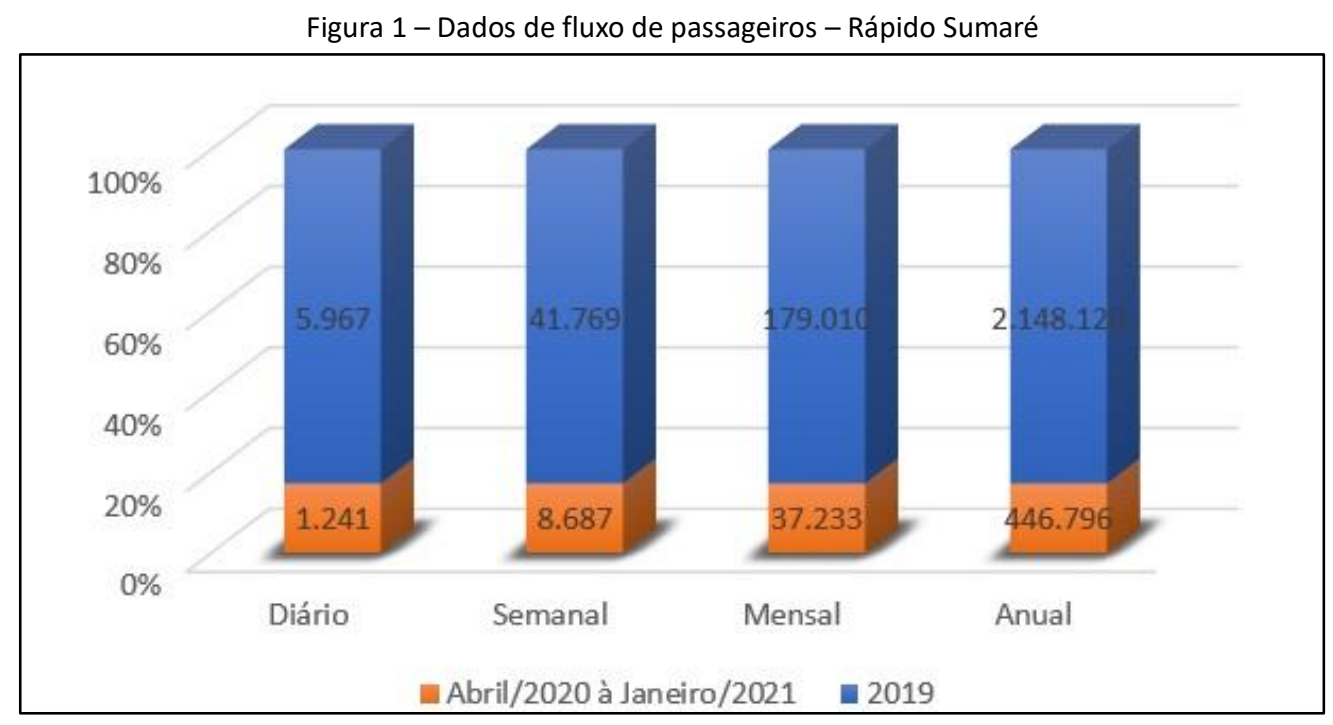

Fonte: Elaborado pelos autores (2021)

Referente as bases de resiliência aliadas as condições de manter a oferta de serviço por muito tempo, somadas as perspectivas para o pós- pandemia, a empresa destaca que haverá redução permanente de $30 \%$ na quantidade de passageiros, ou seja, mesmo com a retomada de $100 \%$ na oferta do serviço a demanda de passageiros ficará $30 \%$ menor do que antes da pandemia.

\section{CONCLUSÃO}

Conclui-se com este trabalho que o sistema de transporte coletivo por ônibus em São João da Boa Vista sofreu diretamente os impactos da pandemia, tendo seu fluxo de passageiros reduzido em $79,2 \%$ e foi condicionado a se adaptar a mudanças nesse atual cenário em que a empresa, em específico, mantém o seguimento nos protocolos de saúde e planejamento para a resiliência durante e após essa crise. Diante desse fato, fica evidente que vivemos em um período o qual as empresas pertencentes a esse seguimento econômico, sob efeitos da pandemia, possam recriar, rever conceitos e práticas para a adaptação de seus sistemas de transporte mediante a nova Era que marcará início pós-pandemia.

Assim, diante da situação atual vivida pela maioria das cidades brasileiras, ressalta-se que como o sistema de transportes é um dos serviços urbanos mais afetados, ele deve passar por inovações em seus veículos para se adequarem aos novos protocolos relacionados à pandemia, como medidas preventivas para a não propagação do vírus nesse ambiente de alto risco. Essas mudanças incluem, menores quantidades de passageiros, limpeza constante nos assentos e barras de apoio (balaústres), novos modelos de janelas para que o ar circule, visto que em alguns veículos as janelas não são feitas para serem abertas, como visto no caso do Rio de Janeiro, dentre outras medidas que resguardam os protocolos de saúde. 


\section{AGRADECIMENTOS}

À empresa Rápido Sumaré e Jorge Domingos Scanavachi, gerente do Grupo Belarmino (com sede no município de São João da Boa Vista) o qual a empresa faz parte, pela atenção e a disposição em responder o questionário enviado, assim como tirar dúvidas mediante a pesquisa sobre o fluxo de passageiros.

\section{REFERÊNCIAS BIBLIOGRÁFICAS}

ASSOCIAÇÃO BRASILEIRA DE NORMAS TÉCNICAS. ABNT NBR 15570:2009 - Transporte - Especificações técnicas para fabricação de veículos de características urbanas para transporte coletivo de passageiros. Rio de Janeiro, 2009.

COUTO, C. F. V, MEDEIROS, M.F.P.A, DIAS, C. BRAGA, I. Y. de L. G. ANDRADE, N. P. de A. A pandemia da Covid - 19 e os impactos para a mobilidade urbana. In: 34ํㅡㄹ Congresso de Pesquisa e Ensino em Transporte da ANPET. Anais. Fortaleza, 2020.

GOMIDE, A. A. (2006). Mobilidade urbana, iniquidade e políticas sociais. Políticas sociais: acompanhamento e análise, 12, 242-250. IPEA. Disponível em http://repositorio.ipea.gov.br/bitstream/11058/4511/1/bps_n.12_ensaio5_alexandre12.pdf> Acessado em: $11 / 03 / 2021$.

IBGE cidades. São João da Boa Vista- população. Disponível em https://cidades.ibge.gov.br/brasil/sp/sao-joao-daboa-vista/panorama>. Acesso em 10 de março de 2021.

KNEIB, E. (Org) Projeto e Cidades Centralidades e mobilidade Urbana. Universidade Federal de Goiás. 2014.

LIMA, G. C. L. S., SCHECHTMAN, R., Brizon, L. C., FIGUEIREDO, Z. M. (2020, abril de 2020). Transporte público e COVID19. O que pode ser feito? Rio de Janeiro. Centro de Estudos em Regulação e Infraestrutura da Fundação Getúlio Vargas (FGV CERI).

PORTAL G1- RJ (2020). Ônibus do Rio devem ficar com janelas abertas e sem ar-condicionado durante o verão. Disponível em <https://g1.globo.com/rj/rio-de-janeiro/noticia/2020/10/25/onibus-do-rio-devem-ficar-sem-arcondicionado-e-com-janelas-abertas-e-durante-o-verao.ghtml>. Acessado em: 04 de março de 2021.

PREFEITURA MUNICIPAL DE SÃO JOÃO DA BOA VISTA - PMSBV. Lei complementar no 4.516, de 20 de agosto de 2.019. Plano Diretor., São João da Boa Vista-SP, 2019. Disponível em <http://www.saojoao.sp.gov.br/home/pdfplanodiretor/Plano\%20Diretor\%20Estrat\%C3\%A9gico\%20-\%20Lei\%20n\%C2\%BA\%204516_2019.pdf>. Acessado em 04 de março de 2021. 